\title{
Low Cost Alternative Fuel from Biomass
}

\author{
Dawit Zeru*, Haftom Gebregergis, Medhanie Gebremedhin, Misgina Tilahun, \\ Omprakash Sahu
}

\author{
Department of Biological and Chemical Engineering, MIT, Mekelle University, (TR) Ethiopia \\ Department of Chemical Engineering, KIOT, Wollo University, (SW) Ethiopia \\ *Tel: +251933520653 \\ *E-mail address:ops0121@gmail.com
}

\begin{abstract}
A major challenge for next decades is development of competitive renewable energy sources, highly needed to compensate fossil fuels reserves and reduce greenhouse gas emissions. Among different possibilities, which are currently under investigation, there is the exploitation of unicellular algae for production of biofuels and biodiesel in particular. Microalgae have the ability of accumulating large amount of lipids within their cells which can be exploited as feedstock for the production of biodiesel. The lipid content of different species of microalgae can range from $30 \%-70 \%$ of their dry weight. In this project a microalgae with lipid content of $60.095 \%$ was used. This means that $26 \mathrm{gms}$ of oil was obtained from $42 \mathrm{gms}$ of microalgae sample from which $17.624 \mathrm{gm}$ of biodiesel (FAME) was found at the end of transesterification. Algae biofuels avoid some of the previous drawbacks associated with crop-based biofuels as the algae do not compete with food crops. The favorable growing conditions found in many developing countries has led to a great deal of speculation about their potentials for reducing oil imports, stimulating rural economies, and even tackling hunger and poverty. Strong research efforts are however still needed to fulfill this potential and optimize cultivation systems and biomass harvesting.
\end{abstract}

Keywords: Algae; Bio-energy; Concentration; Fatty acid; Temperature

\section{INTRODUCTION}

Biodiesel is a biofuels that, through transesterification, can be produced from different feedstocks, including grease, vegetable oils, waste oils, animal fats, and microalgae. In this reaction, triglycerides are converted into fatty acid methyl esters (FAMEs) in the presence of an alcohol, such as methanol or ethanol, and either an alkaline or acidic catalyst. The reaction produces two immiscible layers, biodiesel and, as a byproduct, glycerol [1]. The unstable price of fossil fuel, worldwide interest in reducing the amount of $\mathrm{CO}_{2}$ emitted into the atmosphere, and the attempts of petroleum-dependent countries to enlarge their energy matrix have led to increasing interest in biofuels production. Until recently, the synthesis of biodiesel derived mostly from terrestrial plants[2]. This strategy has become controversial because of the lack of sustainability of plant-based biofuels, specifically; the resulting deforestation of extensive land otherwise devoted to the cultivation of soybean, palm, sugarcane, rapeseed, 
and other food plants the consumption of scarce water resources, the degradation of arable land, and the reduced amount of $\mathrm{CO}_{2}$ fixation [3]. Moreover, the transformation of primary food resources into biofuels has led to a clash of interests, as plant-derived biodiesel has deprived poor countries of food and increased its cost [4]. This has stimulated the search for other sources of biodiesel production, ones that are both sustainable and economical [5]. Microalgae are microscopic heterotrophic-autotrophic photosynthesizing organisms that inhabit many different types of environments, including freshwater, brackish water, and seawater. More than 40,000 different species of microalgae are known, most of which have a high content of lipids, accounting for between 20 and $50 \%$ of their total biomass [5]. Accordingly, microalgae have the potential to synthesize 30 times more oil per hectare than terrestrial plants. They are widely used in industry in the synthesis of pigments and additives, as a source of protein, and in biofuels production [6].

Marine microalgae shows several advantages compared to other sources of biodiesel production: Their high growth rate has the potential to satisfy the enormous demand for biofuels but they can be cultured on non-agricultural land or even in coastal areas and without the need of freshwater. In addition, the tolerance of microalgae to a high $\mathrm{CO}_{2}$ content in gas streams allows high-efficiency $\mathrm{CO}_{2}$ mitigation [7, 8]. Biodiesel from microalgae does not contain sulfurs, is highly biodegradable, and is associated with minimal nitrous oxide release. Microalga farming is also potentially more cost-effective than conventional farming [9]. Microalgae with a high content of fatty acids, neutral lipids, and polar lipids as well as a high growth rate in the natural environment have yet to be exploited for biodiesel, and the isolation and characterization of microalgae with the potential for more efficient lipid/oil production remain subjects of research [10]. A high content of fatty acids, as a neutral lipids or triacylglycerols (TAG), is found naturally in a group of microalgae, the dinoflagellates. Additionally, these organisms occasionally form explosive and extensive proliferations (blooms) in coastal waters all over the world. These episodic blooms extend for hundreds of kilometers and their cell concentrations are in the millions per liter [11]. These properties make din flagellates of potential interest as a source of biofuels.

Nowadays the demand of energy in the world is becoming high. Ethiopia's demand for electricity and petroleum fuels will grow at 11.6 per cent and 9.3 per cent per year, respectively [12]. But crop plants grow in arable land with slow rate and despite the fact that petroleum oil is non-renewable it is also costly to import and it is not environmentally friendly due to its high $\mathrm{Co}_{2}$ emission. These drawbacks of the two sources of energy triggered us to find better source of energy. On average, $93 \mathrm{~g} / \mathrm{m}^{2} /$ day and $32 \mathrm{ml} / \mathrm{m}^{2} /$ day of biomass and oil yield would be possible in the Ethiopian condition. Finally we came with algae as a renewable source of biofuels. Biofuels production from algae is a new clean/green technology that has much indispensable importance [13].

The main aim of this work is to produce biodiesel from local cultivated algae. The production of biodiesel was carried out with transesterification method. This technology is a clean technology in that it makes use of carbon dioxide in the environment. It also replaces the energy that could be found from fossil fuels which non- renewable and can be dangerous to humans and animals when burned. 


\section{MATERIAL AND METHODS}

\section{Material}

Sample (Algae): The sample was collected from natural ponds, northern part of Mekelle city. In this project $10 \mathrm{~L}$ volume of pond was constructed at a place where there is high $\mathrm{CO}_{2}$. It was prepared with $5 \mathrm{~L}$ of water, $2 \mathrm{~g}$ of NPK fertilizer and allowed to be operated for three more days. After a week the pond content appeared to be green as the algal biomass started to be formed.

Harvesting Method: Harvesting is carried out by filtration, centrifugation, flotation, and flocculation of sample. Filtration is carried out commonly on membranes of modified cellulose, with the aid of a suction pump.

Algae Biomass Drying: The algae sample which is going to be used in the extraction process has to be in powder form in order to increase its surface area exposed to the solvent [14]. The algae was placed at the inside window of the laboratory for three days. The dried algae was ground using mortar and pestle. $42 \mathrm{gms}$ of algae powder was obtained.

\section{Methods}

Oil Extraction Method: The oil extraction was carried out with chemical method (Solvent Extraction Method). Benzene and hexane are used as solvent, which is economical and safe. Soxhlet extraction apparatus was set up and placed on a mantle heater and two thimbles filled with $21 \mathrm{gms}$ of the algal powder were inserted into the soxhlet tubes each. The borated flask was filled with $225 \mathrm{ml}$ of cyclo-hexane. The condenser of the soxhlet extraction apparatus was connected to a water tank and then mantle heater was set on. The extraction process was allowed to be operated for about three hours while recycling the water that passes through the condenser. At the end of the extraction process, mixture of the solvent and crude oil was obtained. This mixture was treated with water in order to separate the lipid from the other components and was sent to a rotary evaporator for separating the solvent from the crude oil [15]. The experiment setup is shown in Fig.1.

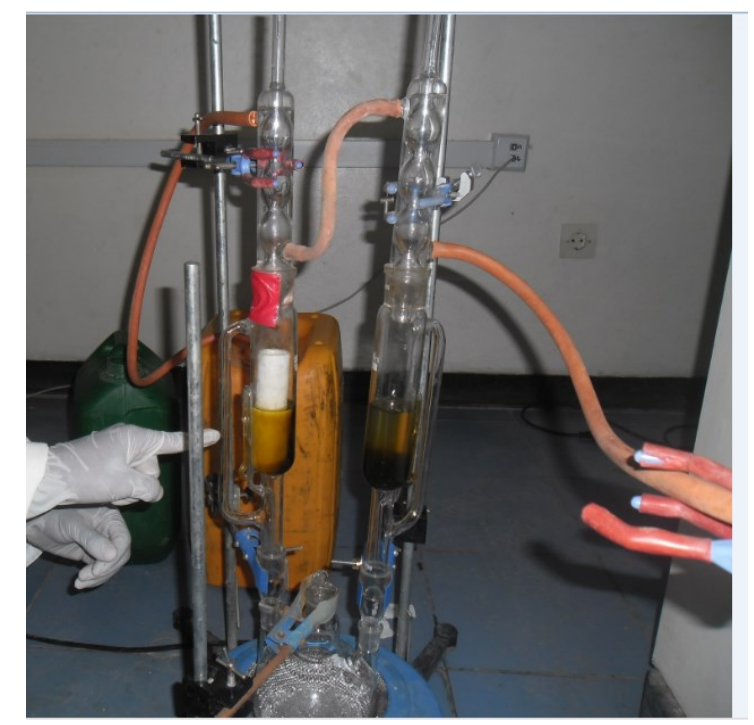

Figure 1. Soxhlet apparatus set up. 
Separation of Crude Oil from Solvent: The result of the soxhlet extraction is a mixture of the crude oil and the solvent. The solvent needs to be separated and recovered for another extraction process and the crude oil goes for the next process (transesterification process). The mixture of the crude oil and solvent in the borated flask was poured to the $500 \mathrm{ml}$ pot. The pot was placed on the water bath being connected to the condenser, and the vapor collecting flask to the other side of the condenser. Completing the setup, power was on and run for half an hour at a temperature of $82^{\circ} \mathrm{c}$. Finally $26.5 \mathrm{gm}$ of crude oil was obtained.

Biodiesel Production Method: Trans-esterification process is used for the conversion of algal oil into biodiesel. Transesterification of algal oil is normally done with methanol and $\mathrm{NaOH}$ serving as the catalyst. The $26.5 \mathrm{gm}$ of crude oil obtained was heated for 15 minutes at a temperature of $50^{\circ} \mathrm{C}, 2 \mathrm{gms}$ of $\mathrm{NaOH}$ was dissolved in $156 \mathrm{ml}$ of methanol and this mixture was added to the flask which contained the heated crude oil and then this mixture was placed on a magnetic stirrer which was set at a temperature of $40^{\circ} \mathrm{C}$ and $300 \mathrm{rpm}$. The magnetic stirrer was turned on and allowed to be operated for three hours. This result was then added to a separator funnel and was left for three days [16]. The FAME (Fatty Acid Methyl Esters), which is the light phase and the glycerol, which is the heavy phase was separated. The glycerol was removed to leave the FAME (biodiesel) in the flask.

\section{Analysis}

Physicochemical Parameters: The physico-chemical properties were examined with standard method, the generated date was compared with the desired qualities standards. Boiling point of the biodiesel, its viscosity, as well as its melting point are some of the chemical properties; color, ignition property, odor and lubricity are some of the physical properties that can be used in characterizing the biodiesel [17]

Results and discussion:The experimental results obtained from the Soxhlet extraction of crude algal oil for $4 \mathrm{hrs}$ is reported in the Table 1.

Table 1. Experimental results of algal oil extraction.

\begin{tabular}{|c|c|c|c|}
\hline S.No & No. of trails & Wt. of oil obtained(gm) & Wt. cake (gm) \\
\hline 1 & Sample- 1 & 24.4 & 17.6 \\
\hline 2 & Sample-2 & 26.5 & 15.5 \\
\hline
\end{tabular}

The above result is obtained using $42 \mathrm{gm}$ of dried algal sample and $225 \mathrm{ml}$ of solvent (cyclohexene) at constant temperature and extraction time.

\section{Sample-1}

$$
\begin{gathered}
\% \text { of oil content }=\left[\begin{array}{c}
\text { wt. oil obtained } / \text { wt. sample }] \times 100] \\
=[24.4 \mathrm{gm} / 42 \mathrm{gm}] \times 100 \\
=58.096 \%
\end{array}\right.
\end{gathered}
$$

$$
\begin{aligned}
\text { Percentage of cake }= & {[\text { wt. cake/wt. sample }] \times 100 } \\
& =[17.6 \mathrm{gm} / 42 \mathrm{gm}] \times 100 \\
& =41.904 \%
\end{aligned}
$$




\section{Sample-2}

$$
\begin{aligned}
& \text { Percentage of oil }=[\text { wt. oil } / \text { wt. sample }] \times 100 \\
& =[26.5 \mathrm{gm} / 42 \mathrm{gm}] \times 100 \\
& =60.095 \%
\end{aligned}
$$

Percentage of cake $=[\mathrm{wt}$. of cake/wt. of sample $] \times 100$

$$
=[15.5 \mathrm{gm} / 42 \mathrm{gm}] \times 100=36.904 \%
$$

The experimental results obtained (shown Table X) was carried out in the trials with constant sample weight, Soxhlet extraction type, temperature, using cyclohexene as a solvent for 4 hours. As a result $58.096 \%$ and $60.095 \%$ of oil content was obtained for the sample 1 and 2 respectively. Under optimum conditions up to $70 \%$ of oil can be extracted from algal biomass. But our result is somewhat less and this is may be due to lack of resources and facility of the laboratory, the solvent used was cyclohexene instead of n-hexane for the extraction process.

After esterification and transesterification biodiesel obtained, whose physical and chemical properties is mention in Table 2. The physical-chemical properties of generated biodiesel were compared with ASTM value it was found all values are satisfactoriness.

Table 2. Comparatively result biodiesel with ASTM.

\begin{tabular}{|c|c|c|c|}
\hline S.No & Biodiesel properties & Measured values & ASTM Standard \\
\hline 1 & Density at $20^{\circ} \mathrm{C}\left(\mathrm{kg} / \mathrm{m}^{3}\right)$ & $839-843$ & $875-900$ \\
\hline 2 & Kinematic viscosity $40^{\circ} \mathrm{C}\left(\mathrm{mm}^{2} / \mathrm{s}\right)$ & $2.90-4.50$ & $1.9-6.0$ \\
\hline 3 & Flash point $(\mathrm{C})$ & $132-150$ & $\geq 130$ \\
\hline 4 & Acid value $(\mathrm{mg} \mathrm{NaOH} / \mathrm{g})$ & $0.68-0.89$ & $<0.8$ \\
\hline 5 & Saponification value $(\mathrm{mg} \mathrm{NaOH} / \mathrm{g})$ & $115.5-124.5$ & $<0.03$ \\
\hline 6 & Moisture content $\%(\mathrm{w} / \mathrm{w})$ & $0.011-0.019$ & $<0.02$ \\
\hline 7 & Ash content\% $(\mathrm{w} / \mathrm{w})$ & $0.019-0.029$ & $<120$ \\
\hline 8 & Iodine value $(\mathrm{I} / \mathrm{g} / 100 \mathrm{~g})$ & $65.6-74.87$ & $>47$ \\
\hline 9 & Cetane number & $70.25-76.46-$ & - \\
\hline
\end{tabular}

Effect of Temperature: The response surface, Fig. 2(a), obtained from operating temperature and crude oil to methanol ratio is flatly convex but had sharply up warded edges at one symmetry suggesting that there are well-defined optimum operating conditions. 
However, the convexity was not high enough, as the surfaces were rather symmetrical about the yield (vertical) axis and a little flat near the optimum which meant that the response optimized value based on combined effects reaction temperature and soapstock to methanol molar ratio may not vary widely from the single variable optimized condition [18]. Contour plot and interaction graph showing predicted response of methyl ester yield as a function of reaction temperature and soapstock to methanol molar ratio is shown in Fig. 2(b). It is indicated that the methyl ester yield is sensitive to reaction temperature and crude oil to methanol molar ratio. An increase in methyl ester yield is observed with the increasing of reaction temperature. It could be interpreted that, under much excess amount, the methanol was used to improve the solubility of crude oil in methanol and reaction mixture would become well mixed. But when lower amount of alcohol were used the increase in temperature decreases the methyl ester yield, this could be due to the reversible nature of the esterification reaction. That is, as the reaction temperature was increased at lower excess alcohol amount the yield is initially maximum and a further rise in temperature favors the water formed during the reaction to hold a reversible reaction to form oil decreasing the yield [19].
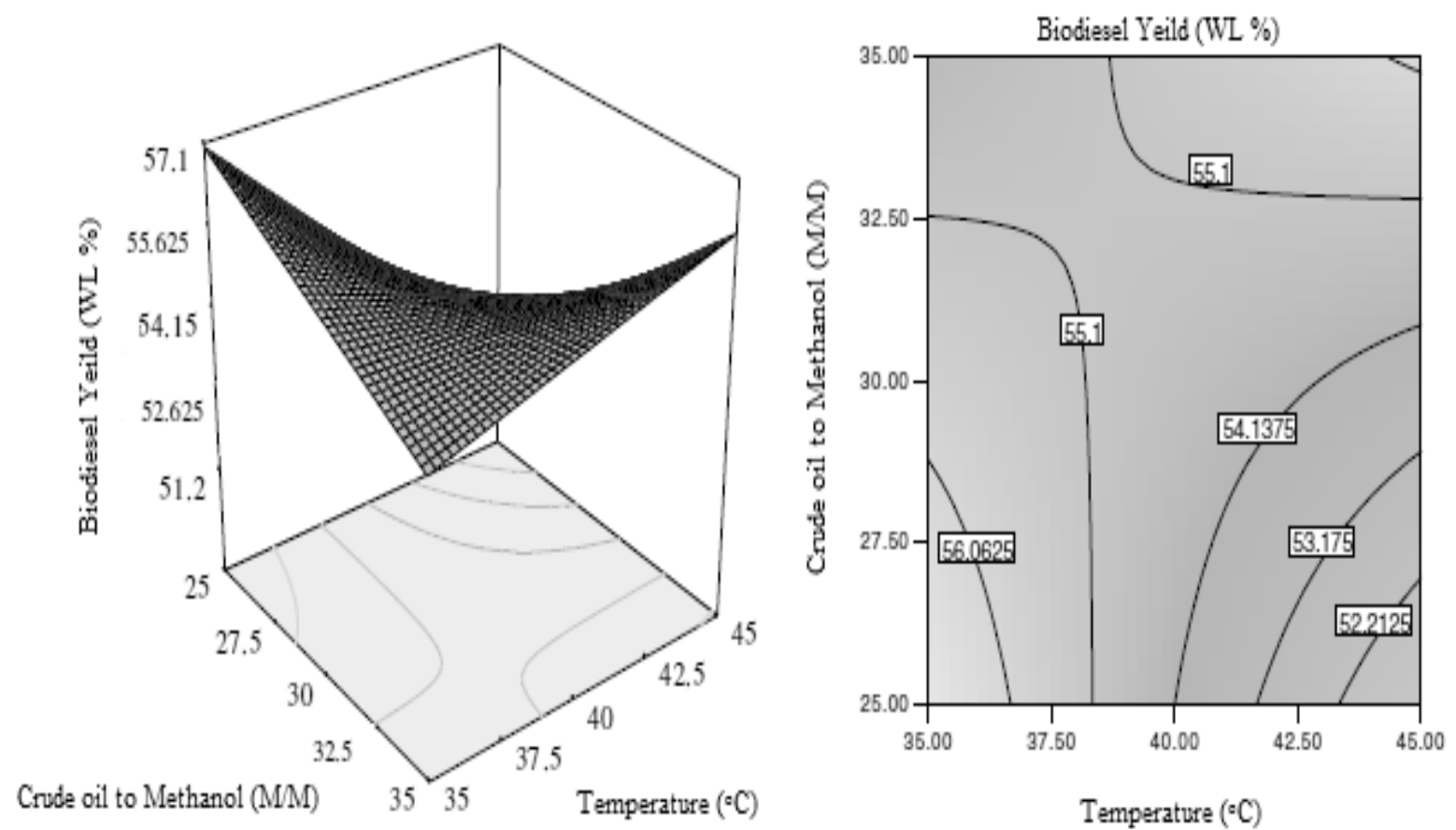

Figure 2. RSM plot for Effect of temperature on biodiesel production.

Effect of reaction time: The response surface, Fig. 3(a), obtained from operating temperature and reaction time is faintly flat and sloppy which has one up warded edge at one end suggesting that there are well defined optimums operating conditions. Moreover, the surface is somewhat flat near the optimum which meant that the response optimized value based on combined effects reaction temperature and reaction time may not vary widely from the single variable optimized conditions. It could be interpreted that, at higher reaction temperatures, there is a chance of loss of methanol when the reaction time increases. The profile of the contour plot, Fig. 3(b) indicated that the interaction between the reaction temperature and amount of soapstock to methanol ratio is strong [20,21]. 

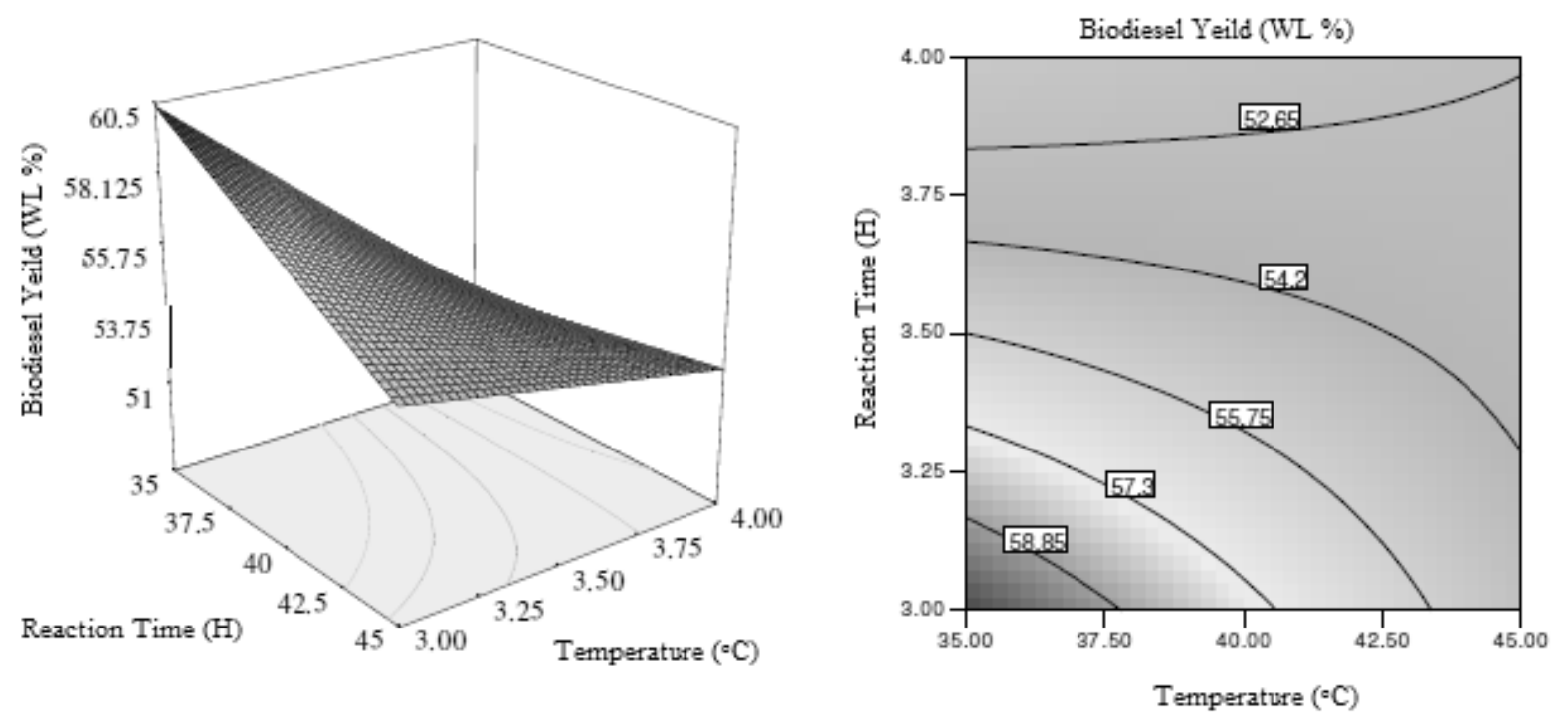

Figure 3. RSM plot for Effect of reaction time on biodiesel production.

\section{Effect of concentration}

The response surface, Fig. 4(a), obtained from soapstock to methanol molar ratio and reaction time was sloppy flat and which had one up warded edge at one end suggesting that there were a dominance of reaction time in the in the interaction of these two factors. The profile of the contour plot, Fig. 4(b), indicated that the interaction between the reaction duration and amount of crude oil to methanol ratio is dominated by reaction duration. It could be interpreted that, at higher reaction temperatures, there is a chance of loss of methanol with longer reaction duration and basically the esterification reaction was kinetics limited so that the yield was faster initially but later the yield decreases due to reversible nature [22].
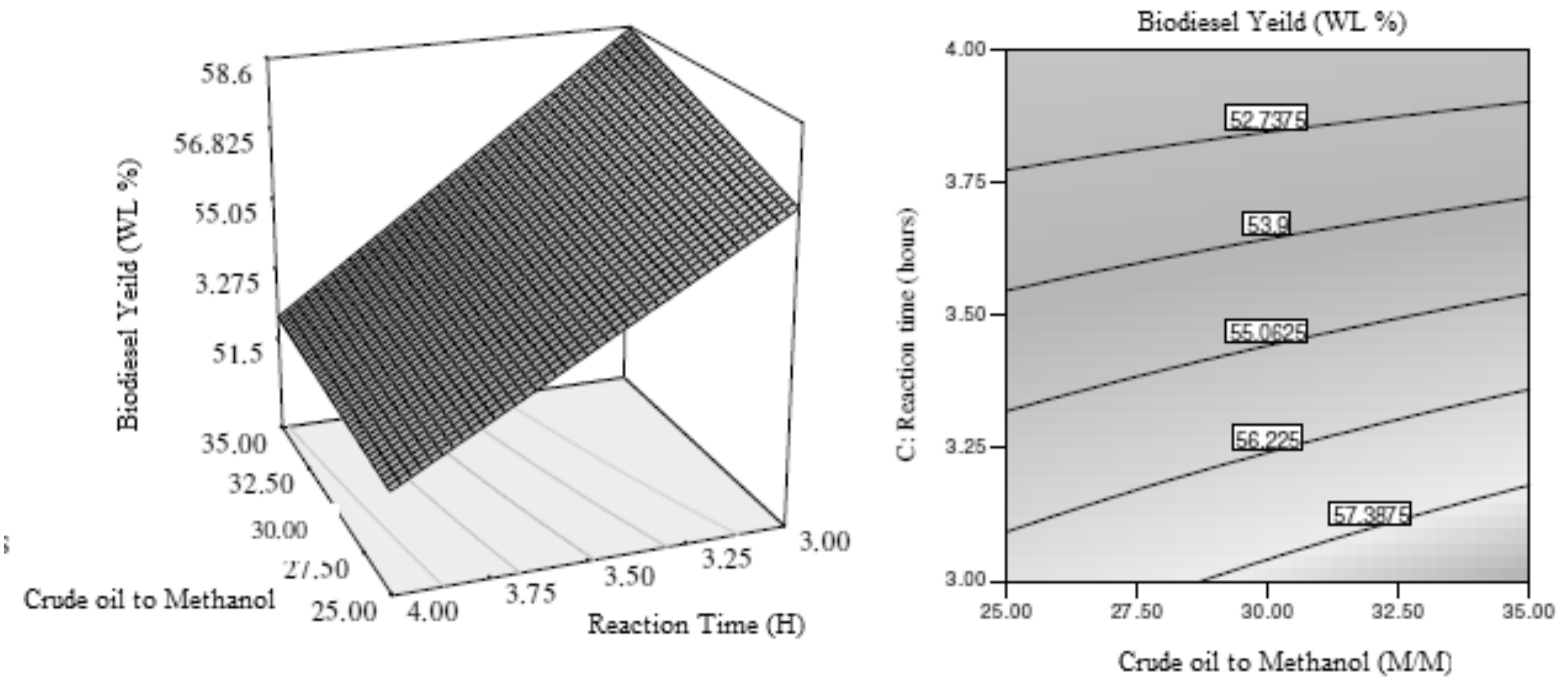

Figure 4. RSM plot for Effect of crude methanol ratio on biodiesel production. 
Optimization of biodiesel: The above results have shown that the three transesterification process variables and their interactions among the variables affecting the yield of biodiesel. Using the optimization function in Design Expert 7.0.0., it was predicted that at $45^{\circ} \mathrm{C}$ reaction temperature, crude oil to methanol ratio of 1:25 and catalyst weight $2 \mathrm{gm}$, an optimum biodiesel yield of $60.095 \%$ was obtained. The optimization is shown Fig. 5 (a) and Fig. 5(b).
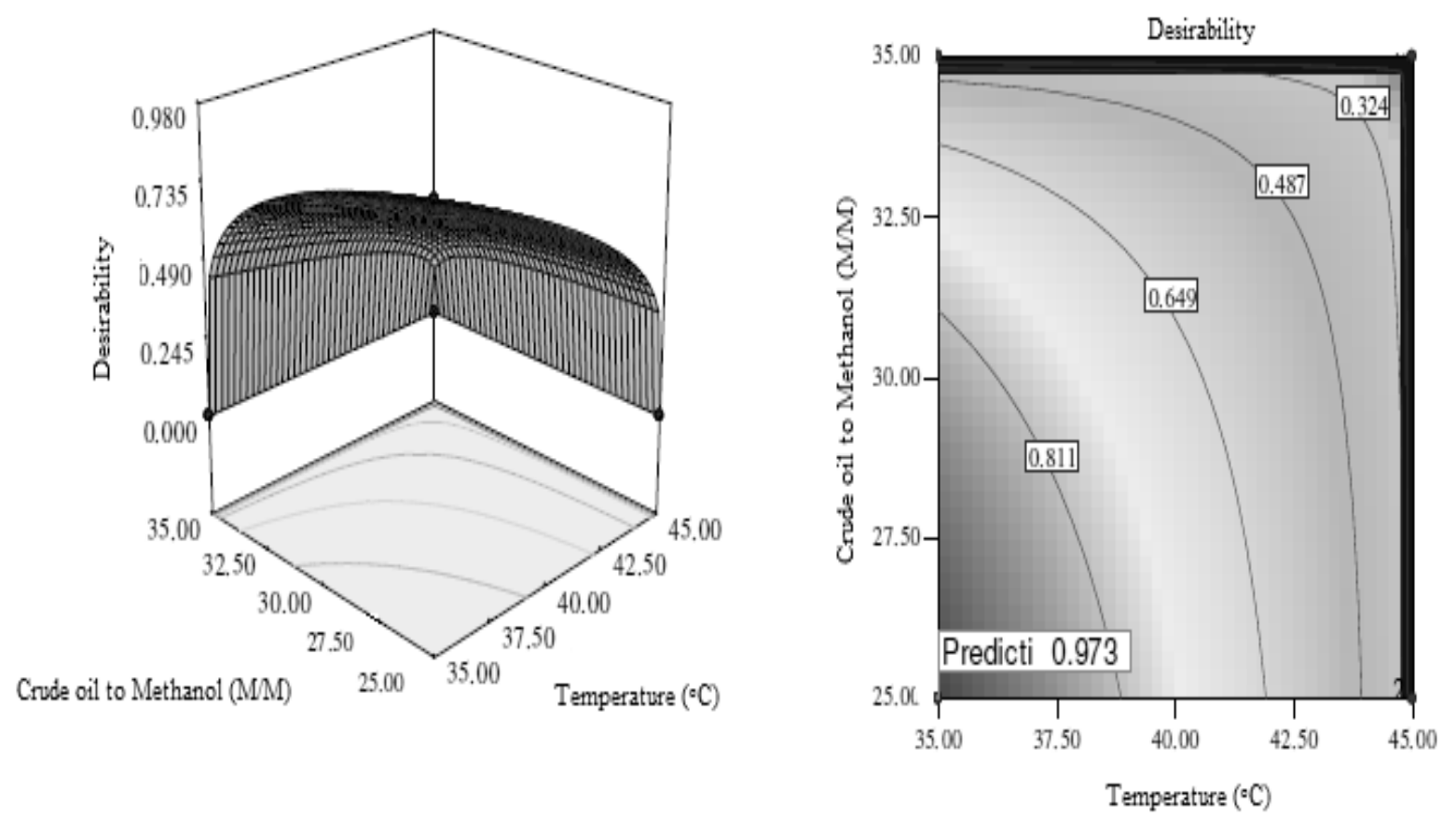

Figure 5. Optimization of biodiesel production.

\section{Conclusion}

The work has been was successful in producing biodiesel, which is fatty acid methyl ester (FAME) by transesterification. Produced biodiesel is less viscous than the biofuels that can be produced from crop plants and it releases relatively less $\mathrm{CO}_{2}$ to the environment. The minimum condition for production of biodiesel was $45^{\circ} \mathrm{C}$ reaction temperature, crude oil to methanol ratio of $1: 25$ and catalyst weight $2 \mathrm{gm}$, was yield of $60.095 \%$. . Microalgae are photosynthetic microorganisms that can produce lipids, proteins and carbohydrates in large amounts over short periods of time. These products can be processed into both biofuels and useful chemicals. Most current research on oil extraction is focused on microalgae to produce biodiesel from algal-oil. Algal-oil processes into biodiesel as easily as oil derived from landbased crops. Algae biomass can play an important role in solving the problem between the production of food and that of biofuels in the near future. 


\section{References}

[1] Schlagerman P, Gottlicher G, Dillschneider R, Rosello-Sastre R, Posten C, (2012). Composition of Algal Oil and Its Potential as Biofuel. Poulickova, A., P. Hasler, et al. (2008). "The ecology of freshwater epipelic algae: an update. Phycologia , 437-450.

[2] Ehimen EA, Sun ZF, Carrington CG, (2010). Variables affecting the in situ transesterification of microalgae lipids. Fuel, 89(3): 677-684.

[3] Li Y, Han D, Hu G, Dauvillee D, Sommerfeld M, Ball S, Hu Q, (2010). Chlamydomonas starchless mutant defective in ADP-glucose pyrophosphorylase hyper-accumulates triacylglycerol. Metable Engineering, 12: 387-391.

[4] Pyle, DJ, Garcia RA, (2008). Producing docosahexaenoic acid (DHA)-rich algae fromBiodiesel-derived crude glycerol: Effects of impurities on DHA production and algal biomass composition. Journal of Agricultural and Food Chemistry, 103 (1): 3933-3939.

[5] Chisti, Y., (2007). Biodiesel from microalgae Biotechnology Advances 25(3): 297301.

[6] Sanchez A, Gonzalez A, Maceiras R, Cancela A, Urrejola S., (2011). Raceway pond design for microalgae culture for biodiesel. Chemical Engineering Transition, 64: 845-50.

[7] Carla S, Jones Stephen P, Mayfield, (2012). Algae biofuels: versatility for the future of bioenergy: available at www.sciencedirect.com, 5-6.

[8] Benemann JR, Oswald WJ, (1993). Systems and economic analysis of microalgae ponds for conversion of carbon dioxide to biomass. Final Report: Grant No. DEFG22-93PC93204. Pittsburgh Energy Technology Center, Pittsburgh, PA, US Department of Energy.

[9] Hannon, M, Gimpel J, Tran M, Rasala B, Mayfield S, (2010). Biofuels from algae: challenges and potential, Biofuels 763-784.

[10] Basha, SA, Gopal KR, Jebaraj, S. (2009). A review on biodiesel production, combustion, emissions and performance. Renewable and Sustainable Energy Reviews, 13 (6-7): 1628-1630.

[11] Simionato D, (2013). Optimization of light use efficiency for biofuel production in algae, Biophysical Chemistry, 39(1): 45-52.

[12] Abraham M, Asmare, Berhanu A, Demessie, Ganti S, Murthy, (2013). Theoretical Estimation of Algal Biomass Potential and Lipid Productivity for Biofuel Production in Ethiopia. International Journal of Science and Research , 45: 285-294.

[13] Williams PJ, Laurens LM, (2010). Microalgae as biodiesel and biomass feedstocks: Review and analysis of the biochemistry, energetic and economics. Energy and Environmental Science, 3: 554-557.

[14] Doucha J, Livansky K, (2006). Productivity $\mathrm{CO}_{2} / \mathrm{O}_{2}$ exchange and hydraulics in outdoor open high density microalgal (Chlorella sp.) photobioreactors operated in a Middle and Southern European climate. Journal of Applied Physiology 18: 811-815. 
[15] Ranjan A, Patil C, Moholkar VS., (2010). Mechanistic assessment of microalgal lipid extraction. Industry Engineering and Chemistry Research, 36: 2979-81.

[16] Zhang BY, Geng YH, Li ZK, Hu HJ, Li YG., (2009). Production of astaxanthin from Haematococcus in open pond by two-stage growth one-step process. Aquaculture; $275-278$.

[17] Veillette M, Chamoumi M, Nikiema J, Faucheux N, Heit M, (2012). Production of Biodiesel from Microalgae. Journal of Chemical Engineering and Biotechnological Engineering Department, 8-11.

[18] El Sikaily, A., A. Khaled, (2006). Removal of Methylene Blue from aqueous solution by marine green alga Ulva lactuca. Chemistry and Ecology 22(2): 149-151.

[19] Kebede-Westhead E, Pizarro C, (2006). Treatment of swine manure effluent using freshwater algae: Production, nutrient recovery, and elemental composition of algal biomass at four effluent loading rates. Journal of Applied Physiology 18(1): 41-46.

[20] Sander K, Murthy GS, (2010). Life cycle analysis of algae biodiesel. International Journal of Life Cycle Assessment, 34: 704-707.

[21] Michael B. Johnson, (2009). Microalgal Biodiesel Production through a Novel Attached Culture System and Conversion Parameters. Journal of Biological Systems Engineering, 4-9.

[22] Bai M, Cheng C, Wan H, Lin Y, (2011). Microalgae pigments potential as byproducts in lipid production. Journal of the Taiwan Institute of Chemical Engineers, 42 (5): 783-786. 